PAPER

\title{
What is it to do good medical ethics? From the perspective of a practising doctor who is in Parliament
}

\author{
Ilora G Finlay
}

\section{Correspondence to}

Prof Baroness llora G Finlay of Llandaff, House of Lords, Westminster, London SW1A OPW, UK; finlayi@parliament. uk

Received 5 October 2014 Revised 15 October 2014 Accepted 22 October 2014
CrossMark

To cite: Finlay IG. J Med Ethics 2015:41:83-86.

\section{ABSTRACT}

This article is a personal reflection on work as a physician with work as a member of the UK Parliament's House of Lords. Ethical thinking should underpin everything we do; the 'four principles' of medical ethics provide an applicable and relevant ethical framework. This article explores its application in both domains of work - as a clinician and as a legislator-with some examples of its use 'to do good medical ethics' in both roles. Debates around tobacco and drug control, pandemic control, abortion and assisted suicide are explored.

Perhaps the better question to ask is 'How can one live without a good ethical framework to underpin all you do?' with a supplementary: 'Where are the boundaries of medical ethics?' Much is written about ethical thinking as underpinning difficult decisions in clinical practice, but in fact every clinical decision must be formed around such a framework - the degrees of difficulty emerge only as the complexity of the decision is understood and as the outcomes of the decision become apparent.

As a parliamentarian, my decisions must also be ethical and must include-whether in relation to health policy or other matters-the anticipation of unintended harmful consequences. As a doctor in Parliament, I have an additional duty to ensure that the humanitarian aspect to decisions is not lost under economic or other pressures, by bringing clinical evidence and reality to inform debates. Disease and injury have complex effects on individuals and families, and the vulnerability that is part of the human condition crosses social-economic and political boundaries.

\section{THE BRITISH BICAMERAL PARLIAMENTARY SYSTEM}

The House of Lords and the House of Commons have different and complementary roles. The appointed House of Lords has three main functions. First, it examines and amends as necessary all legislation either before or after it has passed through its stages in the Commons. Second, it holds the government of the day to account through oral and written questions. Third, Peers examine issues in depth through select committee inquiries and through debates. Each of these functions needs an ethical framework to underpin thinking and decisionmaking, whether it is over foreign policy, humanitarian aid, or aspects of domestic policy. But when there is deadlock, the convention is that the 'will of the elected House' prevails.

Select Committees of both Houses investigate policy and aspects of healthcare with impressive rigour. In both Chambers of Parliament, Human Rights are considered and referred to on an almost daily basis, weighing up one course of action against another. This is done by members of both Houses of Parliament, very few of whom are clinically trained. Yet the core principles of the classical framework outlined by Beauchamp and Childress can be seen to come into play. ${ }^{1}$ When problems are exposed, particularly in healthcare, a failure to respect one or more of the principles of respect for autonomy, beneficence, non-maleficence and justice is usually evident.

When it comes to voting, 'free votes' are rare. In general, party members vote obediently along party lines, although the unpaid peers of the House of Lords are more likely to abstain or vote against a policy with which they disagree because they are not career politicians. Those of us who are independent Crossbench Peers are in the one group that consistently votes on issues on the basis of our understanding of the issue; if we don't understand the issue, we abstain.

\section{PRECEDENT AND RISK}

Each piece of legislation can set a precedent for other changes. New policies, promoted for good reason, can risk impairing current systems that function well through disproportionate regulation and bureaucracy. Raanan Gillon's concept of 'scope' perhaps is the best fit for 'unintended consequences': ${ }^{2}$ intended benefits for one group may produce unintended harms for another, and when such conflicts arise judgement will always be necessary. Such judgements themselves may produce unintended harms by setting precedents.

The risk-averse culture evident across much of health management can at times inhibit actions that might be beneficial for an individual patient. In clinical medicine, risks have to be taken in the pursuit of overall benefit, although non-maleficence is an important moral principle, and everything should be done to minimise the risk of foreseeable unwanted consequences, but not at the cost of the desired good consequences.

\section{RISK AVERSION IN CLINICAL PRACTICE}

In clinical practice, unconventional action can sometimes benefit patient and staff. 
A lonely dying man refused all help, fearing for his adored dog's future; the dog was his raison d'etre. The solution was to admit the dog with him to a hospice single room. His symptoms improved dramatically, staff ran voluntary rotas to walk and feed the dog, and one nurse offered to adopt him. After a short ceremony, the dog went to her home, and within a short time the calmed patient died. No one came to harm, no infection occurred, yet the effect on staff was dramatic as morale rose through a sense of joint purpose.

Such a solution in today's environment needs someone prepared to tackle risk-averse attitudes, and the four-principles framework can help. The patient's autonomy was respected, the dog's presence did not impinge on others' autonomy, benefits to the patient outweighed risks and burdens to both him and others, and in terms of distributive justice, the patient's care was optimised, yet fewer resources were consumed than if the failing efforts at home care had been continued.

However, risk aversion can also result in coercion of patients. With home care encouraged, frail patients are frequently told that they must be on a hospital bed to be nursed at home. Patients feel they have no option. Yet patient autonomy requires voluntary consent, informed by accurate facts.

The evidence behind insistence on such beds is weak at best, and the benefits are speculative. The risk of pressure sores developing can be partly mitigated by a pressure-relieving mattress overlay. The risk to staff of bending over can be partly mitigated by raising a low bed slightly on bricks. As for justice, these hospital-type beds are expensive and often in short supply.

The burdens for the patient include the emotional upheaval of their home being disrupted and of being deprived of physical closeness and warmth, and the risk of falling when trying to get out of an unfamiliar bed. And patients know their deathbed is being delivered and that probably others have died on the bed before them. As one man said, transfer of his severely disabled wife on to such a bed marked the end of their marriage by destroying their ability to be close.

\section{RISK AVERSION IN POLICY}

In theory, legislation could be considered unethical without a strong evidence base, planned evaluation and a preparedness to review or reverse the decision, but, in practice, political pressures can make that impossible.

Take the decision to prohibit possession of khat. ${ }^{3}$ The argument was that London was becoming the centre of khat trafficking in Europe, but, for the community who use khat, there are concerns that domestic problems may worsen if it is not available. As in clinical scenarios, a central question is whether the harms outweigh the benefits-leaving khat available or prohibiting it. Only time will tell.

\section{FOCUSING POLICY ON THE IMPORTANCE OF RESEARCH AND EDUCATION IN HEALTH}

In terms of risk versus benefit, clinical research has gone through difficult times. Fear of unethical or poorly conducted research fuelled a tightening of research controls that then became a major barrier to research in the UK. Yet research is the only way to prove benefit and to advance healthcare. Doctors in both Houses of Parliament raised the topic time and again, through debates such as mine on Academic Health Partnerships in $2010,{ }^{4}$ in many amendments throughout 2011 to the Health and Social Care Bill, ${ }^{5}$ and in various inquiries of Select Committees.

The roll-out of beneficial lessons from research depends on education and training, hence the importance of the amendments to the Health and Social Care Act that created a duty of education and training. Now that the Health Committee in the House of Commons is chaired by Sarah Wollaston MP, a general practitioner herself, the practical importance of healthcare ethics in daily practice is being brought to one of the most influential and important Parliamentary Committees.

\section{DISTRIBUTIVE JUSTICE, WHO BENEFITS?}

The current humanitarian disaster of Ebola may be in part a consequence of delayed action internationally to support rigorous disease-control measures in a desperately poor part of the world. ${ }^{6}$ Charities such as Medecins sans Frontières, not governments, were at the vanguard of generous professionals selflessly going to work in affected areas. The World Medical Association, led by the British Medical Association, has unanimously called all governments to act; they have a moral duty to help those in Africa, and the consequences of inaction are too terrible to contemplate. Such distributive justice is important for its own sake, as well as to decrease the risks of harm to others. A failure to help those in need abroad may deliver untold harms on us as well as them.

\section{UNINTENDED CONSEQUENCES}

However carefully legislation is considered, unintended consequences can occur. Take David Steele's Abortion Act of 1967, legislation that came about when desperate women were dying at the hands of backstreet abortionists. ${ }^{7}$ Clinicians of the day will recall the horrors of young women dying of haemorrhage or sepsis, of women whose uterus had been perforated, and of infertility as a result of such practices. Many campaigned for such legislation. But parliamentarians supporting the bill on its passage through Parliament did not envisage that pregnancy terminations would increase in England and Wales to over 180000 in 2013 performed solely on the grounds of risk to a woman's physical or mental health if the pregnancy continued (often dubbed 'social abortion'), nor that selective abortion of female fetuses might be undertaken in the name of cultural choice, even though that remains illegal.

Now that early medical abortion is physically safer than the continuance of a pregnancy with its inherent risks, campaigners want to remove any restrictive assessment. Opponents want, on moral grounds of respect for the life of the fetus, to tighten the criteria because improved neonatal care has allowed survival at a younger gestational age. If Parliament should reconsider this, Gillon's notion of scope may help those at each end of the spectrum of belief, as well as those in between who see the developing fetus as gradually acquiring moral status, to understand how deeply conscientious thinkers who agree that we must not murder innocent people may nonetheless hold deeply opposing views about abortion. ${ }^{8}$ Be that as it may, currently the parliamentary solution appears to rest with the steady state of the status quo.

\section{AUTONOMY, CHOICE AND TOBACCO CONTROL}

Autonomy and personal choice have been used as powerful arguments against tobacco control. They have centred on an individualistic interpretation of autonomy, expressed as personal choice, and meaning 'I want therefore I get', but ignoring the inter-relational aspect of our lives. Yet the autonomy of one person must not impede or restrict the autonomy of another; concern for others sometimes has to over-ride concern for and rule of oneself. The tobacco lobby argued that an advertising ban curtailed consumer 'choice'. Opposing arguments 
concerned public health; the wishes of an individual should not be allowed to harm others in society, especially the vulnerable.

I supported the ban on tobacco advertising, proposed a private members bill to prohibit smoking in public places in Wales, and now actively support standardised packaging of tobacco products and prohibition of smoking in cars when minors are present. The risks to young people of addiction to nicotine and the health harms of passive smoking outweigh the argument of individualism. As for justice, the costs to the NHS and to society of tobacco-related disease and premature death outweigh the income to the exchequer from taxation on tobacco products.

A clear example of relational autonomy is seen when individual autonomous wishes conflict; democratic societies need rules about what people can and cannot do. Take a simple example: some people may well feel safer if they carried a knife or firearm on our city streets at night, but in the UK we prohibit the carrying of weapons because we have democratically decided that the risk to others outweighs the benefit to the individual. The potential for misuse is too great. By contrast, in the USA, the possession of firearms is viewed as a fundamental right for self-defence; despite the catalogue of aggressive shootings there, attempts to curb the US gun lobby have consistently failed.

\section{ASSISTING SUICIDE-THE DEBATE}

Parliament currently faces the complex issue of physicianassisted suicide and/or euthanasia (PAS/EU). For some people who are in distress, this can seem to be the only option, often portrayed in the media as a temptingly simple solution to the very complex problem of where the limits, if any, of our duty of care lie and what might be the unintended harmful consequences of legislative change to the 1991 Suicide Act.

For most parliamentarians, whether of religious faith or none, this question is one of the most difficult facing our society: whether we should allow one person to be directly involved in deliberately foreshortening another's life. Such a decision is fundamentally different from decisions to withhold or to cease treatments that are failing to achieve their therapeutic goal.

Those arguing for PAS/EU cite autonomy as a key argument, often speaking in terms of 'that is what I would want for myself'. But there are difficulties with this. First, no one knows what they will want until they are in a situation. I have known many say "I wouldn't want to live if ....", yet when that very situation arises, a powerful will to live is at odds with their previously expressed wish. Second, such an approach falls into the trap of ignoring the relational aspects of people in society, in communities and in families, and that the actions of one person affect others, directly or indirectly.

The tragedy of an individual's suicide is a solitary action the impact of which lives on 'in the memory of those left behind'. In assisted suicide, a second person is involved in, and can influence, another's suicide; the involvement has a direct effect on this person, as well as an indirect effect on others and on society's values.

The balancing of factors around beneficence and nonmaleficence will be achieved differently by different people depending on the relative weights they afford to the importance of benefit versus avoiding harm, and also the weight they give to respect for autonomy. Again, these different perspectives are seen in the text of the parliamentary debates that have already occurred. Those arguing for assisted suicide and EU state that the benefit to a person to be dead and the benefit of respecting their autonomous wishes outweighs the benefit of their continued existence.
To opponents, the risk of an invalid decision and the risks to others from a change in the law are too great. Risks that undermine such a decision, including misdiagnosis and misinformation about prognosis and coercion, whether internal to the person or external pressures, all outweigh the certainty required to view such a final act as appropriate.

\section{VALID DECISION-MAKING}

Just as with any major decision, whether to have surgery, to buy a house or to send the country to war, there are three conditions for a valid decision.

First, there needs to be accurate information. Take buying a house: it was the frequent problems with surveys that led to the Housing Act in 2012, stipulating that the seller must produce an accurate information pack about the property. Similarly but far more seriously, when it comes to the decision to end your life, accurate information is needed, yet post mortem research consistently shows significant errors, including misdiagnosis of terminal illness resulting in inappropriate treatment, in around five per cent of cases. ${ }^{9}$ To quote the Royal College of General Practitioners' evidence to the Select Committee on Lord Joffe's Bill, 'it is possible to make reasonably accurate prognoses of death within minutes, hours or a few days. When this stretches to months, the scope for error can extend into years'. ${ }^{10}$

Second, you need to have the mental capacity to take the decision to seek assisted suicide-the Oregon evidence seriously undermines claims that this is possible. Capacity to take such a decision must be commensurate with the decision being taken. Yet, impairments to capacity are common in the seriously ill. Depression, severe enough to reach 'caseness' on full testing and that probably would respond to treatment, is difficult to diagnose in the terminally ill.

A study from Oregon followed 18 patients who had requested PAS and had passed all the assessments to obtain lethal drugs. Half the cohort (nine patients) went on to die by ingesting lethal drugs, legally supplied under Oregon's physician-assisted suicide law, but three of them were assessed by the independent researchers as reaching 'caseness' for depression on assessment. Thus one in six of the original group who passed all the assessment tests for PAS actually had an undiagnosed and untreated depression. It would seem that the duty of care-beneficence with minimal harm-had failed. In the words of the report, 'the current practice of the Death with Dignity Act in Oregon may not adequately protect all mentally ill patients'. ${ }^{11}$ Oregon Health Department reports reveal that psychiatric evaluation does not happen as frequently as would be expected. ${ }^{12}$

Evidence from psychiatric evaluations in this country similarly reveals the degree of impairment missed in routine practice by most practitioners, as about one-third of those with neurological disease have mental capacity impaired to an extent that throws serious doubt on the validity of such a major decision as to have assistance with suicide. ${ }^{13}$ But the most common reason for capacity being impaired is as a result of medication that the person is receiving. Steroids distort emotional responses in many patients, along a spectrum that, in a few, is exhibited as a frank psychosis. Opioids can cause clinical depression over time, as can many other drugs.

Third, for a decision to be valid, it must be voluntary. This causes real difficulties when the decision is very major and the potential sources of coercion are many and varied. Take the patient who feels they are a burden, who perhaps is aware that their care at home is pushing up fuel bills in the winter, who sees the family becoming exhausted with caring, who worries about future costs should care needs increase or who is coming 
under pressure, however subtle, because there is an inheritance at stake-these are very real situations in today's society. And healthcare professionals can also be inadvertently coercive with negative attitudes, with careless words that portray to the patient that they are a burden in the system-terms such as 'bedblocker' or 'non-compliant' are denigratory and demoralising. Added to this is the influence of the communication and relational skills of the professionals themselves; a sense of hopelessness in professionals is conveyed to patients. ${ }^{14} 15$ Hopelessness and depression are pathways to despair and linked to higher levels of a desire for death in patients. ${ }^{16}$

Legislation sets society's rules. It is there to protect the vulnerable from those of ill-intent in society. Currently the law protects the vulnerable from the coercive pressures described above. Those with severe disability often describe difficulty accessing optimistic healthcare and find that people are too ready to give up on them. To remove protection from encouragement to suicide from one group-those who appear to be terminally ill -is to say that they deserve less protection in law. It gives a value statement that their lives are of less value than the lives of others who are not terminally ill, for whom society has extensive suicide-prevention policies.

\section{LEGISLATION OVERALL}

Most legislative bodies depend on voting to agree new legislation. When there is gridlock, as seen when the two Houses of the US legislature have different majorities, the direction of government can almost grind to a halt. But inclusive government comes at a price; there are times when those elected are under pressure to vote along political lines even though they feel uncomfortable doing so. It is a brave politician who feels so strongly that he or she defies their party whip; it can be the end of any hopes of achieving ministerial or other positions of office.

As politicians weigh up issues in the scales of justice, they need to keep the other scales in mind. Doing good and avoiding harm is not always easy. Our autonomy in society is relational- our actions affect others. ${ }^{17}$ Unfettered individualism is a dangerous way to interpret autonomy because, at its extreme, it is lawlessness. There is a burden of responsibility on all legislators to ensure that ethical principles govern their decisions, even when these appear to be in conflict with their personal or party interests; bad decisions come back to haunt us.

Competing interests LGF is the Director of Living and Dying Well.

Provenance and peer review Commissioned; internally peer reviewed.

\section{REFERENCES}

1 Beauchamp TL. Childress JF. Principles of biomedical ethics. 6th edn. Oxford University Press, 2009.

2 Gillon R. Medical ethics: four principles plus attention to scope. BMJ 1994;309 (6948):184-8.

3 Misuse of Drugs Act 1971 (Amendment) (No.2) Order. House of Lords Hansard. 12 May 2014.

4 Academic Health Partnerships, House of Lords Hansard. 29 Nov 2010.

5 Health and Social Care Act. 2012. http://services.parliament.uk/bills/2010-12/ healthandsocialcare/stages.html (accessed 2 Oct 2014).

6 House of Commons Report 247 (Session 2014-15), Page 3.

7 The Abortion Act. 1967. http://www.legislation.gov.uk/ukpga/1967/87/contents (accessed 5 Oct 2014).

8 Gillon R. Is there a new ethics of abortion? J Med Ethics 2001;27(Suppl 2):ii5-9.

9 House of Lords Report 86-II (Session 2004-05), Page 730.

10 House of Lords Report 86-II (Session 2004-05), Page 80.

11 Ganzini L, Goy ER, Dobscha SK. Prevalence of depression and anxiety in patients requesting physicians' aid in dying: cross sectional survey. BMJ 2008;337:a1682.

12 Oregon Health Authority. 2013. Death with Dignity Act. http://www.healthoregon. org/dwd (accessed 30 Sept 2014).

13 House of Lords Report 86-I (Session 2004-05), Paragraph 125.

14 Buckley J, Herth K. Fostering hope in terminally ill patients. Nurs Stand 2004;19 (10):33-41.

15 Rodin G, Lo C, Mikulincer M, et al. Pathways to distress: the multiple determinants of depression, hopelessness, and the desire for hastened death in metastatic cancer patients. Soc Sci Med 2009;68(3):562-9.

16 Breitbart WS, Rosenfeld B, Pessin H, et al. Depression, hopelessness, and desire for hastened death in terminally ill patients with cancer. JAMA 2000;284:2907-11.

17 O'Neill O. Autonomy and assisted suicide. http://www.livinganddyingwell.org.uk (accessed 12 Oct 2014). 